\title{
Evaluation of practolol in hypertension Effects on sympathetic nervous system and renin responsiveness
}

\author{
M. D. Esler and P. J. Nestel
}

From the Department of Clinical Science, The fohn Curtin School of Medical Research, The Australian National University, Canberra, A.C.T., Australia

The $\beta$-adrenergic blocker, practolol, proved to be an effective antihypertensive agent in a single-blind crossover trial, involving 17 patients with essential hypertension of mild to moderate severity. After a 2-month placebo period, dosage was begun at $100 \mathrm{mg}$ twice a day, and titrated against blood pressure response up to a maximum dose of $400 \mathrm{mg}$ twice a day, leading to an average reduction in blood pressure of $20 / 18 \mathrm{mmHg}$, and satisfactory control in 14 of 16 patients (one defaulter). The clinical and physiological data were analysed for prediction of response to practolol. The urinary noradrenaline response to head-up tilt, an index of the responsiveness of the sympathetic nervous system, correlated significantly with subsequent blood pressure reduction with practolol $100 \mathrm{mg}$ twice a day $(r=0.62, P<0.01)$. In 8 patients, responsiveness to tilt was retested after control of blood pressure: changes in diastolic blood pressure and pulse rate while on practolol were both significantly less than pretreatment responses. The urinary noradrenaline response was also reduced $(+0.50 \mu \mathrm{g} / \mathrm{hr}$ vs. pretreatment mean of $+I .64 \mu \mathrm{g} / \mathrm{hr} ; P<0 \cdot 0 \mathrm{I})$, a finding not explicable in terms of known receptor-blocking properties of the drug. It is suggested that the antihypertensive action of $\beta$-adrenergic blockers may be related to a reduction in the reflex activity of the sympathetic nervous system.

Plasma renin activity, which was normal in the recumbent state, rose with tilting. The response with tilt was significantly reduced with practolol, though plasma renin activity during recumbency was only marginally lowered by the drug.

Although $\beta$-adrenergic blocking drugs are finding increasing application in the treatment of hypertension, the mechanism by which they lower blood pressure remains uncertain. The antihypertensive effect has been attributed to a reduction in cardiac output (Fröhlich et al., 1968) but a satisfactory reduction in blood pressure with oral medication has been stated to occur after a latent period of several weeks (Prichard and Gillam, 1969), whereas the effect on cardiac output is rapid. An unexplained phenomenon is the extreme range of sensitivity to the blood pressure-lowering effects of $\beta$-blockers shown by essential hypertensives, dose requirements of propranolol varying between perhaps $0 . I$ and $3 \mathrm{~g}$ daily (Zacharias, 197 ; Prichard, 1970).

Essential hypertensives exhibit a broad range of sympathetic nervous system responsiveness when subjected to postural stresses, extending from underactivity in patients responding to tilting with posReceived 26 September 1972. tural hypotension, through to increased activity in so-called 'orthostatic hypertensives' who display greater than normal rises in blood pressure and noradrenaline (Fröhlich et al., 1967; Esler, 1970). On the basis of our earlier studies (Esler, 1970), we have investigated the relation between sympathetic responsiveness to change in posture and subsequent sensitivity to the blood pressure-lowering effect of a $\beta$-adrenergic blocker.

Oral administration of propranolol produces a fall in blood pressure which is associated with a reduction in cardiac output, but total peripheral vascular resistance is increased (Fröhlich et al., 1968). The relative contribution of reflex vasoconstriction and blockade of $\beta$-adrenergic vasodilator receptors in skeletal muscle to this rise in vascular resistance is not clear. The 'cardioselective' $\beta$ adrenergic blocker, practolol, has a lesser effect on vessels in skeletal muscle than propranolol (Barrett, 197I). This might be advantageous in the treatment 
of hypertension, and the efficacy of practolol as an antihypertensive agent has been assessed in the present study.

\section{Patients and methods}

\section{Patients}

The study was performed on 17 patients (8 male, 9 female), average age 38 years (range 21-56), with essential hypertension. All had sustained hypertension of mild to moderate severity. These subjects were drawn from a consecutive series of $4 \mathrm{I}$ patients with untreated essential hypertension referred for investigation and treatment. No patient with a history of bronchospasm, Raynaud's phenomenon, or cardiac failure was included in the study (2 exclusions on these grounds). Also excluded were patients with borderline hypertension, obese hypertensives in whom weight reduction was also indicated, and patients with severe hypertension whose need for blood pressure reductions was too urgent to be compatible with the design of the trial. Average pretreatment blood pressure for the group was $164 / 107 \mathrm{mmHg}$ (range 150/95-I80/I18), and severity index (Corcoran et al., 1954) 2.5 (range $0-4 \cdot 0$ ). The diagnosis of essential hypertension was reasonably established by routine screening tests including urine microscopy and culture, serum and 24-hour urinary sodium and potassium, endogenous creatinine clearance, urinary catecholamines, and intravenous pyelography. None of the female patients was taking oral contraceptive drugs. The majority of the patients had received no previous treatment for hypertension; 4 had been treated in the past, but not in the preceding I2 months.

\section{Laboratory investigations}

Changes in blood pressure with tilting, urinary noradrenaline (corrected for changes in glomerular filtration rate), and plasma renin activity were measured. The experimental procedure was as follows: after an overnight fast, subjects were rested supine in a single-bed ward for 90 minutes before the beginning of the study, at the end of which they emptied their bladder. Smoking was forbidden, and drinking water was given throughout to ensure an adequate urine flow. Then after 90 minutes of recumbent rest, a timed urine sample was collected for assay of catecholamines and creatinine. Blood was drawn at this stage, after 3 hours of recumbency, for assay of serum creatinine and plasma renin activity. When blood pressure had stabilized after the venepuncture, the patients were tilted head-up at $25^{\circ}$ on a tilttable for a further 90 minutes. Blood pressure was measured at frequent intervals with a sphygmomanometer, with the cuff at heart level. At the end of this period of tilt, further samples of blood and urine were collected for assay of catecholamines, creatinine, and plasma renin activity.

Urinary free noradrenaline and adrenaline were determined in duplicate using the method of Crout (196I), by differential fluorimetry using 2 sets of filters (von Euler and Lishajko, I959).

Urinary creatine was measured by a modification of the alkaline picrate method (Edwards and Whyte, 1958), serum creatinine by autoanalyser.

Plasma renin activity was determined by the bioassay method of Skinner (1967) using the anaesthetized ganglion-blocked rat. The difference between 24 duplicate measurements of plasma renin activity was $6 \pm 9$ per cent (mean \pm standard deviation). The assay was performed in duplicate on 2 different rats, and was repeated if duplicates differed by more than 24 per cent (mean difference $+2 S D$ )

\section{Drug trial design}

The antihypertensive effect of practolol was evaluated in a single-blind crossover trial in which a placebo was given for $\mathbf{2}$ months followed by a fixed dose of practolol, IOO $\mathrm{mg}$ twice daily, for 6 months. The dose was then titrated against blood pressure response up to a maximum dose of $400 \mathrm{mg}$ twice a day. The pretreatment blood pressure value was the mean of 4 readings obtained from two-weekly outpatient attendances over the 2 months on placebo. There was no fall in blood pressure during this time. The treatment blood pressure on the $100 \mathrm{mg}$ twice daily dose schedule was the mean of all outpatient readings taken at intervals of 2 to 3 weeks over the past 4 months of the 6-month period on practolol. If the recumbent blood pressure exceeded 150/90 $\mathrm{mmHg}$ after 6 months, the dose was increased until blood pressure was reduced to this level, or until an arbitrary maximum dose of $400 \mathrm{mg}$ twice a day was being given. Lying blood pressures were measured, by a single observer with a sphygmomanometer bag, dimensions $30 \times 12.5 \mathrm{~cm}$, after 3 to 5 minutes of recumbent rest. Standing blood pressures were measured after the patient had been standing for I to 2 minutes.

\section{Results}

The effect of practolol $100 \mathrm{mg}$ twice daily on pulse rate and supine and standing blood pressures is shown in the Table. Significant reductions in systolic and diastolic blood pressure and pulse rate occurred on the drug. The falls in supine and standing pressures were of similar magnitude.

Practolol proved to be clinically effective as the sole antihypertensive agent in these patients with mild to moderately severe sustained hypertension. Using a recumbent blood pressure of $150 / 90 \mathrm{mmHg}$ as a therapeutic endpoint, in 7 of 17 patients control was achieved with a dose of $100 \mathrm{mg}$ twice daily, a further 5 required $200 \mathrm{mg}$ twice daily, and another 2 patients $400 \mathrm{mg}$ twice daily. Since there was one defaulter, a dose of up to $400 \mathrm{mg}$ twice daily resulted in satisfactory control in 14 of 16 patients. At the upper dose level the mean reduction in recumbent blood pressure was $20 / 18 \mathrm{mmHg}$.

The drug was well tolerated and in particular there were no recorded instances of postural or exercise-induced hypotension. A maculopapular rash, constipation, lethargy, and vivid dreams was 
TABLE Mean response to practolol $100 \mathrm{mg}$ twice daily

\begin{tabular}{|c|c|c|c|c|}
\hline & Placebo & $\begin{array}{l}\text { Practolol } \\
\text { roo mg } \\
\text { twice daily }\end{array}$ & Reduction & $\begin{array}{l}\text { Significance } \\
\text { level } \star\end{array}$ \\
\hline \multicolumn{5}{|l|}{ Supine } \\
\hline Systolic blood pressure (mmHg) & 164 & 148 & I6 & $P<0.00 I$ \\
\hline Diastolic blood pressure & 107 & 94 & 13 & $P<0.01$ \\
\hline Pulse rate $/ \mathrm{min}$ & 80 & 70 & I0 & $P<0.05$ \\
\hline \multicolumn{5}{|l|}{ Standing } \\
\hline Systolic blood pressure & 160 & 146 & I4 & $\mathbf{P}<0.01$ \\
\hline Diastolic blood pressure & III & 98 & 13 & $\mathbf{P}<0.001$ \\
\hline
\end{tabular}

each observed once, but did not require treatment to be stopped.

The rate of fall of blood pressure on a constant dose of $100 \mathrm{mg}$ practolol twice daily is shown in Fig. I. In the 7 patients who were controlled on this dose, the maximum fall in blood pressure had virtually been attained by the time of the first outpatient attendance after 2 weeks of treatment (Fig. I). There were no delayed falls in these patients, or in the others with smaller initial responses to this dose. On restarting the placebo, the return of the blood pressure to pretreatment levels was slow, being of the order of 4 to 6 weeks (Fig. I, blood pressure $147 / 95 \mathrm{mmHg}$ after 2 weeks off practolol vs. $162 / 102 \mathrm{mmHg}$ after 6 weeks off practolol; $\mathrm{P}<0.01$ for paired $\mathrm{t}$ test).

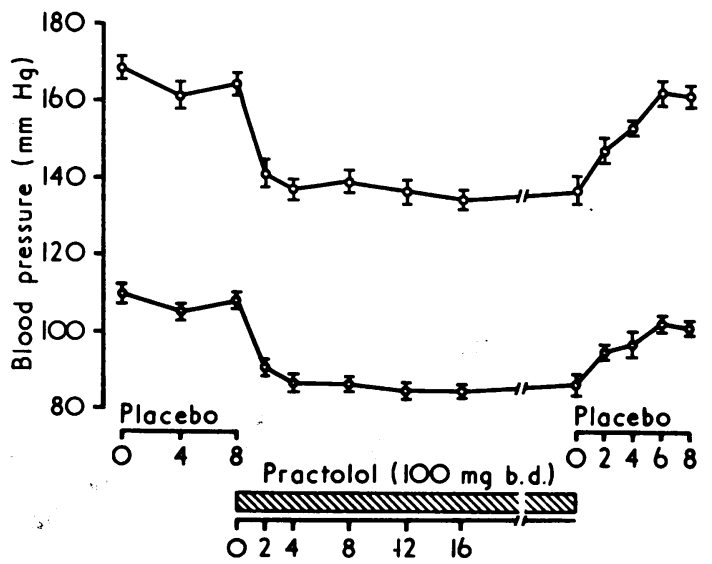

Duration of treatment (weeks)

FIG. I Average outpatient blood pressure in 7 patients whose increase in blood pressure was controlled by a practolol dose of $100 \mathrm{mg}$ twice daily, during intervals on (i) placebo, (ii) constant dose of practolol, (iii) placebo. Means and standard errors are shown.
Some essential hypertensives are very sensitive to the blood pressure-lowering effects of $\beta$-adrenergic blockers. We tried to classify these retrospectively on clinical and physiological grounds. Some indices did not predict sensitivity to practolol. Blood pressure reduction on the low dose was unrelated to the initial level of the blood pressure (within the narrow range encompassed in this study), severity index, resting pulse rate, plasma renin activity, or the supplemental blood pressure (Smirk, 1944) (casual blood pressure minus basal blood pressure, a measure of the lability of the hypertension). The sym-

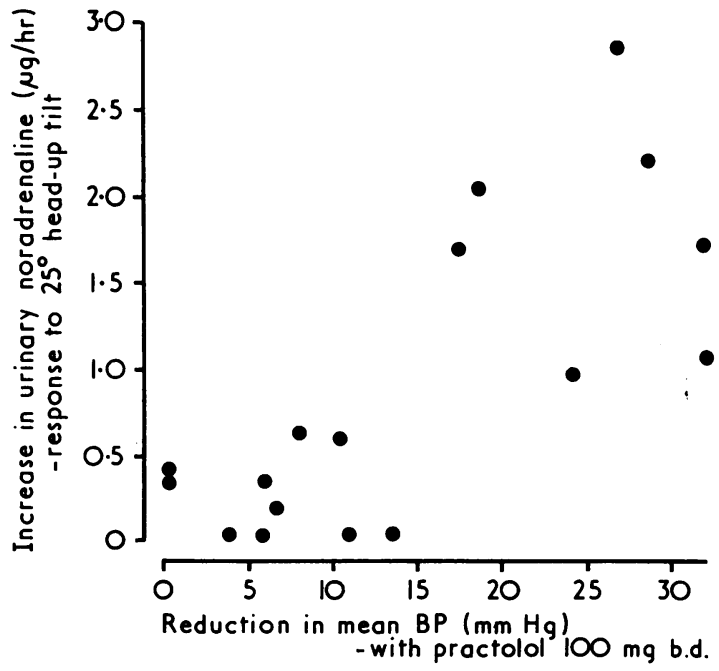

FIG. 2 Relation of pretreatment urinary noradrenaline response to $25^{\circ}$ head-up tilt in 17 patients with essential hypertension, to subsequent fall in mean blood pressure produced by a practolol dose of $100 \mathrm{mg}$ twice daily. $r=0.62, P<0.01$. (Mean blood pressure = $I / 3$ systolic blood pressure $+2 / 3$ diastolic blood pressure.) 
pathetic responsiveness to head-up tilt did, however, correlate with subsequent blood pressure reduction with practolol. When subjected to head-up tilt, essential hypertensives exhibit a broad range of sympathetic responsiveness, ranging from greater noradrenaline and blood pressure responses than occurring in normotensive subjects through to normal or diminished responsiveness (Fröhlich et al., 1967; Esler, 1970). The hyperresponders to tilt, with greater than normal noradrenaline and blood pressure responses, proved to be most sensitive to the blood pressure-lowering effects of practolol at the lowest dosage. Overall there was a significant
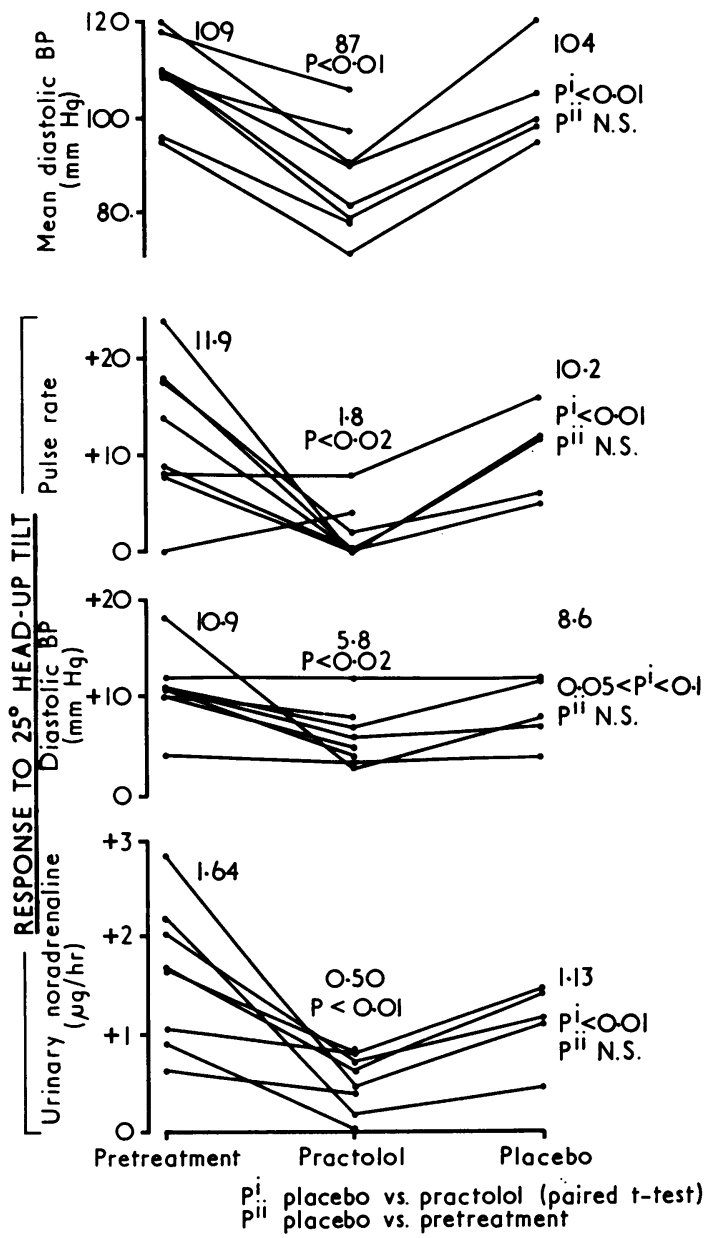

FIG. 3 Average outpatient diastolic blood pressure, and responses in pulse rate, diastolic blood pressure, and urinary noradrenaline to $25^{\circ}$ head-up tilt, in essential hypertensive patients before treatment, after control of the blood pressure by practolol, and on return to a placebo. Means and significant levels are shown. correlation between the urinary noradrenaline response to tilt and subsequent blood pressure reduction $(r=0.62, P<0.01$; Fig. 2$)$. The correlation between diastolic blood pressure response to tilt and subsequent blood pressure reduction on practolol was of a lower order $(r=0.42,0.1>P>0.05)$ but orthostatic hypertensives, with a diastolic blood pressure rise of > $>\mathrm{mmHg}$ (Esler, 1970), as a group had a larger fall in mean blood pressure than the hypertensives with normal or reduced blood pressure responses to tilt (fall in mean blood pressure $23 . \mathrm{I} \pm$ I I $.7 \mathrm{mmHg}$ vs. $10.8 \pm 9.7, \mathrm{P}<0.05)$.

In 8 patients, in whom the blood pressure had been satisfactorily controlled with either $200 \mathrm{mg}$ (7) or $400 \mathrm{mg}$ (I) daily, the responses to tilting were retested after an interval of 9 to 24 months. The blood pressure, pulse rate, and urinary noradrenaline responses were all significantly diminished (Fig. 3). Five of these patients were restarted on placebo, and after an interval of 2 to 3 months during which blood pressures rose to near pretreatment levels, responses were measured a third time. Tilt responses on placebo, including the noradrenaline response, were greater than on practolol, and had returned towards pretreatment figures (Fig. 3).

In 8 patients the effect of practolol on plasma renin activity was measured. Plasma renin activity was measured after 3 to 4 hours of recumbent rest, and after 90 minutes of $25^{\circ}$ head-up tilt, once before treatment, and again on practolol. There was no restriction of dietary sodium intake in these patients. Though big falls in unstimulated plasma renin activity occurred with practolol in the 3 patients in whom it was initially high, the difference overall was not significant at the 5 per cent level; $1 \cdot 91 \pm 0.46$ $\mathrm{ng} / \mathrm{ml} / \mathrm{hr}$ (mean \pm standard deviation) vs. $\mathrm{I} \cdot 25 \pm 0 \cdot 34$ on practolol $; 0.05<\mathrm{P}<0.1$ paired $t$ test. The plasma renin activity response to tilt was significantly diminished on practolol (Fig. $4 ; \mathrm{P}<0.01$ ).

\section{Discussion}

The antihypertensive effect of oral propranolol therapy is associated with a fall in cardiac output, but total peripheral vascular resistance is raised (Fröhlich et al., 1968). Because practolol has much less activity on $\beta$-adrenergic peripheral vasodilator receptors in skeletal muscle than propranolol (Barrett, 197I) and chronic oral administration of practolol is not associated with increase in total vascular resistance (Bodem et al., 1971), it was anticipated that practolol too would lower blood pressure in essential hypertension, and perhaps be more potent in this regard than propranolol. In this trial, practolol proved to be an effective antihypertensive agent in patients with moderate sustained essential hyper- 


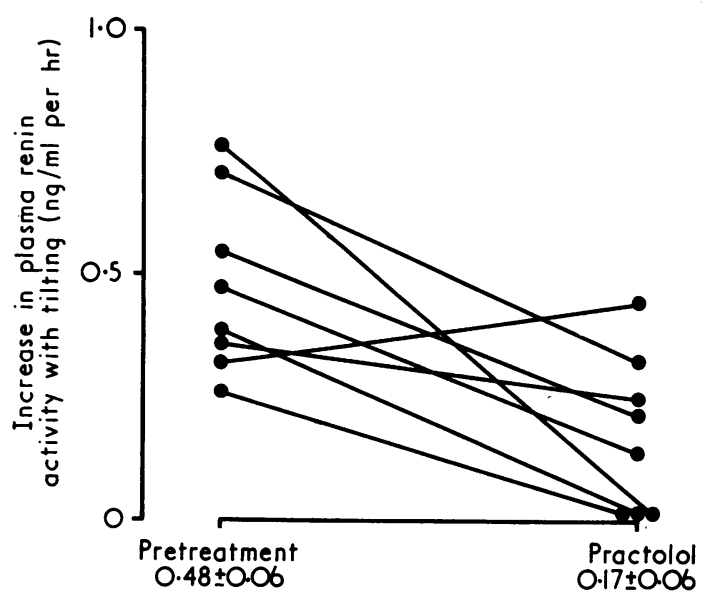

FIG. 4 The effect of oral practolol on the increase in plasma renin activity with tilting. The plasma renin activity response was significantly reduced on practolol $(P<0 \cdot 0 I)$.

tension. A similar finding has been reported by two other groups of workers (Prichard, Boakes, and Day, I97I; Waal-Manning, 1970). The antihypertensive activity relative to that of propranolol remains uncertain. In the only comparative trial (Waal-Manning, 1970), propranolol and practolol were found to be of similar potency, but since a 2-week crossover design had been used, a residual effect on blood pressure from the previous $\beta$-adrenergic blocker may still have been present when the second drug was being evaluated.

As has been found previously with propranolol (Zacharias, I97I ; Prichard, 1970), essential hypertensive patients exhibited a broad range of sensitivities and hence dose requirements, though pretreatment blood pressures were similar. Sensitivity to the blood pressure lowering effect of practolol was unrelated to such variables as the resting pulse rate, and the supplemental blood pressure, a measure of the lability of the hypertension. Only the sympathetic responsiveness to head-up tilt correlated with subsequent sensitivity to practolol. The haemodynamic and noradrenaline response to change in posture was used as an index of 'sympathetic nervous activity'. The urinary noradrenaline response is probably a qualitatively valid if quantitatively inexact index of change in sympathetic activity, and might reflect baroreceptor sensitivity, and the activity of central noradrenergic neurones and peripheral sympathetic nerves. When responsiveness to tilt was reassessed in 8 patients on practolol $(7$ of whom had previously reacted as tilt hyperresponders), response in all was reduced to within the normal range. The fall in the noradrenaline re- sponse is not readily explicable in terms of known receptor-blocking properties of the drug.

The mechanism by which practolol produced this reduction in reflex sympathetic activity is unknown. An increase in blood volume can reduce orthostatic responsiveness (Jeffrey, Fareeduddin, and Abelmann, 1970). Blood volume was not altered by practolol in 3 patients in whom it was measured, and in fact, reduction in plasma volume with propranolol has recently been reported (Tarazi, Fröhlich, and Dustan, 1971). Though there is some indirect evidence of a reduction in baroreceptor sensitivity by propranolol in dogs (Booker et al., 1969), observations in man do not support this finding (Sleight, Gribbin, and Pickering, I97I). An effect on central noradrenergic neurones is a possible explanation since the occasional side-effect of troublesome dreams (Wiseman, I97I) suggests that practolol enters the central nervous system. What relation, if any, this reduction in reflex sympathetic nervous system activity has to the antihypertensive action of the drug is uncertain, but it has often been suggested that repeated, greater than normal, reflex responses to pressor stimuli occurring in borderline hypertension may contribute to the genesis of sustained hypertension.

The search for the best existing drug for a particular patient with essential hypertension is largely a matter of trial and error. With $\beta$-blockers, the main therapeutic guideline relates to the exclusion of certain patients, such as those with uncontrolled heart failure or a history of bronchospasm, there being no clear-cut grounds for preferring this class of drugs to another. Subgroups of patients with essential hypertension may exist who would be expected to be highly sensitive to $\beta$-adrenergic blockers, such as those with 'hyperdynamic $\beta$ adrenergic disease' (Fröhlich, Tarazi, and Dustan, 1969) in whom a raised blood pressure is associated with cardiac symptoms, such as palpitations, and excessive sensitivity to infused $\beta$-agonist can be demonstrated. The orthostatic hyperresponders described in this study may prove to be another group in whom a $\beta$-blocker might be a logical first line drug, though it is clear that with adequate dosage, satisfactory control can be achieved in the majority of hypertensive patients (Zacharias, I97I ; Prichard, 1970).

It has been suggested that other physiological variables, such as plasma renin activity and cardiac output, may be relevant to the different sensitivity shown by individual hypertensive patients to $\beta$ adrenergic blockers. While cardiac output was not measured, evidence exists that orthostatic hypertensives have a higher than average cardiac output (Fröhlich et al., 1967). In the present study, recum- 
bent plasma renin activity before treatment did not correlate with subsequent blood pressure reduction on the low dose of practolol.

The effect of practolol on plasma renin activity is of interest. Unlike propranolol, which has been shown to lower plasma renin activity (Stokes et al., 1970), practolol did not significantly reduce plasma renin activity in recumbency. However, the renin response to tilt was diminished by practolol. The sympathetic nervous system may be involved in the release of renin (Vander, 1967), including, most probably, the renin release with upright posture (Winer et al., 1969). Diminished renin response to tilt during practolol therapy may reflect only the diminished reflex sympathetic responsiveness.

We thank Canberra doctors who referred patients for entry into the trial, in particular Dr. K. Barnes. The supply of practolol tablets by I.C.I. (Australia) is gratefully acknowledged.

\section{References}

Barrett, A. M. (197I). The pharmacology of practolol. Postgraduate Medical fournal, 47, Suppl. 7.

Bodem, G., Brammell, H. L., Weil, J., and Chidsey, C. (1971). Beta blockade in hypertension (abstract). Circulation, 4344, Suppl. 2, 143.

Booker, W. M., West, W. L., Hyde, A. J., and May-Cole, M. (1969). Alteration of the carotid sinus reflex response by propranolol and by alpha methyldopa (abstract). Circulation, 39-40, Suppl. 3, 48.

Corcoran, A. C., Dustan, H. P., Taylor, R. D., and Page, I. H. (1954). Management of hypertensive disease. American fournal of Medicine, $17,383$.

Crout, J. R. (1961). Catecholamines in urine. In Standard Methods of Clinical Chemistry, Vol. 3. Academic Press, by the American Association of Clinical Chemists, New York and London.

Edwards, K. D., and Whyte, H. M. (1958). The measurement of creatinine in plasma and urine. Australian fournal of Experimental Biology and Medical Science, 36, 383.

Esler, M. D. (1970). Neurogenic responsiveness to upright tilt in essential hypertension (abstract). Proceedings of the Australian Society for Medical Research, 2, 351.

Euler, U. S. von, and Lishajko, F. (1959). The estimation of catechol amines in urine. Acta Physiologica Scandinavica, 45, 122.

Fröhlich, E. D., Tarazi, R. C., and Dustan, H. P. (1969). Hyperdynamic $\beta$-adrenergic circulatory state. Archives of Internal Medicine, 123, I.
Fröhlich, E. D., Tarazi, R. C., Dustan, H. P., and Page, I. H. (1968). The paradox of beta-adrenergic blockade in hypertension. Circulation, 37, 4I7.

Fröhlich, E. D., Tarazi, R. C., Ulrych, M., Dustan, H. P., and Page, I. H. (1967). Tilt test for investigating a neural component in hypertension. Its correlation with clinical characteristics. Circulation, 36, 387.

Jeffrey, F. E., Fareeduddin, K., and Abelmann, W. H. (1970). Increased tolerance of patients with circulatory congestion to orthostatic stress. American fournal of the Medical Sciences, 259, 323.

Prichard, B. N. C. (1970). Propranolol as an antihypertensive agent. American Heart fournal, 79, 128.

Prichard, B. N. C., Boakes, A. J., and Day, G. (197I). Practolol in the treatment of hypertension. Postgraduate Medical fournal, 47, Suppl. 84.

Prichard, B. N. C., and Gillam, P. M. S. (1969). Treatment of hypertension with propranolol. British Medical fournal, I, 7.

Skinner, S. L. (1967). Improved assay methods for renin 'concentration' and 'activity' in human plasma. Circulation Research, 20, 391.

Sleight, P., Gribbin, B., and Pickering, T. G. (1971). Baroreflex sensitivity in normal and hypertensive man: the effect of beta-adrenergic blockade on reflex sensitivity. Postgraduate Medical fournal, 47, Suppl. 79.

Smirk, F. H. (1944). Casual and basal blood pressures. IV. Their relationship to the supplemental pressure with a note on statistical implications. British Heart fournal, 6, 176.

Stokes, G. S., Gentle, J. L., Stoker, L. M., Goldsmith, R. F., and Hayes, J. M. (1970). Effects of $\alpha$ - and $\beta$-adrenergic blockade on peripheral and renal vein renin activity in hypertensive patients (abstract). Proceedings of the Australian Society for Medical Research, 2, 354.

Tarazi, R. C., Fröhlich, E. D., and Dustan, H. P. (1971). Plasma volume changes with long-term beta-adrenergic blockade. American Heart fournal, 82, 770.

Vander, A. J. (1967). Control of renin release. Physiological Reviews, 47, 359.

Waal-Manning, H. J. (1970). Comparative studies on the hypotensive effects of beta-adrenergic receptor blockers. In Proceedings of Ciba Symposium, Auckland, N.Z.

Winer, N., Chokshi, D. S., Yoon, M. S., and Freedman, A. D. (1969). Adrenergic receptor mediation of renin secretion. fournal of Clinical Endocrinology and Metabolism, 29, I 168.

Wiseman, R. A. (I97I). Practolol - accumulated data on unwanted effects. Postgraduate Medical fournal, 47, Suppl. 68.

Zacharias, F. J. (197I). Propranolol in hypertension: a 5-year study. Postgraduate Medical fournal, 47, Suppl. 75.

Requests for reprints to Dr. M. D. Esler, The John Curtin School of Medical Research, The Australian National University, P.O. Box 334, Canberra City, A.C.T. 2601, Australia. 